\title{
The Properties of Elasticity, Thermology, and Anisotropy in Pd-Based Alloys
}

\author{
Kuankuan Chen, Meng Hu, Chunmei Li, Guannan Li, Zhiqian Chen* \\ Faculty of Materials and Energy, Southwest University, Chongqing, China \\ Email: ${ }^{*}$ chen_zq@swu.edu.cn
}

How to cite this paper: Chen, K.K., Hu, M., Li, C.M., Li, G.N. and Chen, Z.Q. (2017) The Properties of Elasticity, Thermology, and Anisotropy in Pd-Based Alloys. Journal of Materials Science and Chemical Engineering, 5, 17-34.

https://doi.org/10.4236/msce.2017.53002

Received: March 1, 2017

Accepted: March 28, 2017

Published: March 31, 2017

Copyright $\odot 2017$ by authors and Scientific Research Publishing Inc. This work is licensed under the Creative Commons Attribution International License (CC BY 4.0).

http://creativecommons.org/licenses/by/4.0/

\begin{abstract}
This work is devoted to investigate the elasticity, anisotropy, plastic properties, and thermal conductivity of $\mathrm{PdSnYb}, \mathrm{PdSn}_{2} \mathrm{Yb}$ and Heusler alloy $\mathrm{Pd}_{2} \mathrm{SnYb}$ via employing the first-principles. The magnetic properties of $\mathrm{Pd}_{2} \mathrm{SnYb}, \mathrm{PdSnYb}$ and $\mathrm{PdSn} n_{2} \mathrm{Yb}$ are obtained by the geometry optimization combining with spin polarization. And the stability of these three kinds of materials is ensured by comparing with the enthalpy of formation and binding energy. The Fermi energy has same trend with stability. The details of bulk and Young's modulus are demonstrated in 3D plots, embodied the elastic anisotropies of PdSnYb, $\mathrm{PdSn}_{2} \mathrm{Yb}$, and $\mathrm{Pd}_{2} \mathrm{SnYb}$. The calculations of plastic properties are also anisotropic. And the minimum thermal conductivities are small enough for these three materials to be used as thermal barrier coatings.
\end{abstract}

\section{Keywords}

First-Principles, Pd-Based Alloys, Elasticity, Thermal Conductivity, Anisotropy

\section{Introduction}

Heusler alloys are composed of a series of intermetallics. In recent years, plenty of magnetic properties that Heusler alloys presented and their applications in spintronic devices had aroused wide concern [1] [2] [3]. The properties of Heusler alloys were well diversified, such as non-ferromagnetic elements could exhibit ferromagnetism after highly ordered [4] [5], 100\% spin polarization were presented in materials which were called half-metallic ferromagnets (HMF) [6] [7], only a minority of Heusler alloys containing rare earth had been reported to be superconductors [8] [9] [10], etc. These above features elucidated their potential for future applications in different fields.

As early as $1903, \mathrm{Cu}_{2} \mathrm{MnAl}$ became the prototype of Heusler alloys, since $\mathrm{F}$. 
Heusler [11] firstly reported $\mathrm{Cu}_{2} \mathrm{MnAl}$ and high magnetic ordered alloy of $\mathrm{Cu}_{2} \mathrm{MnAl}$ series. In 1969, P. Webster [12] discussed magnetic and structure properties of Heusler alloys systematically. Liu et al. [13] discovered another highly ordered Heusler alloy, which named $\mathrm{Hg}_{2} \mathrm{CuTi}$. Up to now, more than one hundred kinds of Heusler alloys were found both in theory and experiments, such as Mn-based alloys [14] [15] [16], Co-based alloys [17] [18], Cu-based alloys [19] [20] [21], Ni-based alloys [22] [23]. But the reports about Pd group Heusler alloys were relatively less and the majority of them were related to experiments. Kierstead et al. [24], Aoki et al. [25] [26] and Stanley et al. [8] studied the Heusler compound $\mathrm{Pd}_{2} \mathrm{SnYb}$ and $\mathrm{Pd}_{2} \mathrm{SnEr}$, whose superconductivity and antiferromagnetism were concomitant. Novel properties of thermodynamics and transmission were shown in $\mathrm{Pd}_{2} \mathrm{SnYb}$ obviously. And the superconductivity presented at $T_{\mathrm{c}}=2.3 \mathrm{~K}$, along with a synchronous phase of antiferromagnetism and superconductivity yielding at $T_{\mathrm{N}}=220 \mathrm{mK}$. The testing of elastic and inelastic neutron scattering for $\mathrm{Pd}_{2} \mathrm{SnEr}$ was carried out, which proved that $\mathrm{Pd}_{2} \mathrm{SnEr}$ turned into superconductor at $T_{\mathrm{c}}=1.17 \mathrm{~K}$. Only when temperature conditions met $T>T_{\mathrm{c}}$, the antiferromagnetic correlations would occur. The maximum critical temperature was found in $\mathrm{Pd}_{2} \mathrm{YSn}$, which was revealed as the Heusler alloy [27].

However, in the aspect of theoretical calculation, there is no systematic research on elasticity, thermal properties and anisotropy of Pd-based alloys $\mathrm{PdSnYb}, \mathrm{PdSn}_{2} \mathrm{Yb}$ and $\mathrm{Pd}_{2} \mathrm{SnYb}$ so far. In this work, we provide the overall calculation and analysis of these properties. Especially, once the thermal conductivity is smaller, the heat-shielding performance will be better. The computed minimum thermal conductivities of $\mathrm{Pd}_{2} \mathrm{SnYb}, \mathrm{PdSnYb}$ and $\mathrm{PdSn}_{2} \mathrm{Yb}$ are all less than $0.5 \mathrm{~W} \cdot \mathrm{m}^{-1} \cdot \mathrm{K}^{-1}$. This minimum thermal conductivity is small enough to be applied to thermal barrier coatings and many other fields. Hence, the thorough discussion carried on the three materials is essential, which inspires our passion on studying these materials. And it makes great sense to explore the microstructure and properties of Pd-based alloys.

\section{Calculation Model and Parameters}

\subsection{Model Details}

Pd-based system used in this work includes three alloys: $\mathrm{Pd}_{2} \mathrm{SnYb}, \mathrm{PdSnYb}$ and $\mathrm{PdSn}_{2} \mathrm{Yb}$. The symmetry group and international table number of $\mathrm{Pd}_{2} \mathrm{SnYb}$ are $F \overline{4} 3 m$ and 216. $\mathrm{PdSnYb}$ and $\mathrm{PdSn}_{2} \mathrm{Yb}$ are orthorhombic system. Their space groups are PNMA (No. 62) and CMCM (No. 63). In $\mathrm{Pd}_{2} \mathrm{SnYb}$, Pd possesses the $8 \mathrm{c}$ site $(0.25,0.25,0.25), \mathrm{Sn}$ perches the $4 \mathrm{a}$ site $(0,0,0), \mathrm{Yb}$ possesses the $4 \mathrm{~b}$ site $(0.5,0.5,0.5)$. In PdSnYb, atoms of $\mathrm{Pd}, \mathrm{Sn}$, and $\mathrm{Yb}$ respectively possess the $4 \mathrm{c}$ site $(0.28675,0.25,0.3988),(0.17329,0.25,0.07563)$ and $(0.0176,0.25,0.69161)$. In $\mathrm{PdSn}_{2} \mathrm{Yb}, \mathrm{Pd}$ and $\mathrm{Yb}$ perch the $4 \mathrm{c}$ site $(0,0.70228,0.25),(0,0.42899,0.25), \mathrm{Sn}$ possesses the $8 \mathrm{f}$ site $(0,0.14024,0.04483)$. In order to obtain reliable structural optimization results, the lattice constants we employed are all from experiments. 


\subsection{Parameters Setting}

CASTEP code [28] was used for this work, which grounded on the density functional theory [29]. The exchange correlation functional employed the PBE method in the generalized gradient approximation (GGA) [30]. Ultra soft pseudo potential (USPP) [31] was chosen for interaction potential between ionic potential and valence electrons. The atom orbits $\mathrm{Pd} 4 \mathrm{~d}^{10}$, Sn $5 \mathrm{~s}^{2} 5 \mathrm{p}^{2}$, and $\mathrm{Yb} 4 \mathrm{f}^{14} 5 \mathrm{~s}^{2} 5 \mathrm{p}^{6} 6 \mathrm{~s}^{2}$ were considered as valence electrons in the calculation of pseudo potential. The cut-off energy of $450 \mathrm{eV}$ was set for plane waves in the wave-vector $K$ space. For Brillouin regions $k$-point sampling, the Monkhors-Pack mesh was set as $4 \times 4 \times$ 4 [32]. The lattice parameters of $\mathrm{Pd}_{2} \mathrm{SnYb}, \mathrm{PdSnYb}$ and $\mathrm{PdSn}_{2} \mathrm{Yb}$ were optimized successively by using the BFGS scheme [33] [34] [35] [36]. On this basis, the magnetic, alloy corrosion resistance, elastic, thermal conductivity and anisotropy are being computed.

\section{Calculation Results and Discussions}

\subsection{Magnetic Property}

The equilibrium lattice constants of $\mathrm{Pd}_{2} \mathrm{SnYb}, \mathrm{PdSnYb}$, and $\mathrm{PdSn}_{2} \mathrm{Yb}$ are obtained by geometry optimization with spin polarization. The paramagnetic (NM), ferromagnetic (FM) and anti-ferromagnetic (AFM) coupling between $\mathrm{Yb}$ atoms are taken into account in the calculations. Atomic initial magnetic order affects the convergence of ground state. Therefore, the different magnetic orders of $\mathrm{Yb}$ atoms are considered to ensure the convergence of ground state. In the condition of different magnetic orders, the curves of the relative energy are drawn out in Figure 1, whose minimum energy is set up to be the ground state $(0 \mathrm{eV})$.

As the Figure 1 shown, the energy of AFM-2 (each layer of $\mathrm{Yb}$ atoms spin in the opposite manner along the crystal orientation [001]) in $\mathrm{Pd}_{2} \mathrm{SnYb}$ is higher than other magnetic orders. And this proves spin polarization displaying in $\mathrm{Pd}_{2} \mathrm{SnYb}$. However, the energy of $\mathrm{NM}$ in PdSnYb and $\mathrm{PdSn}_{2} \mathrm{Yb}$ are the highest. It demonstrates the ground state of these three materials, which is in accordance

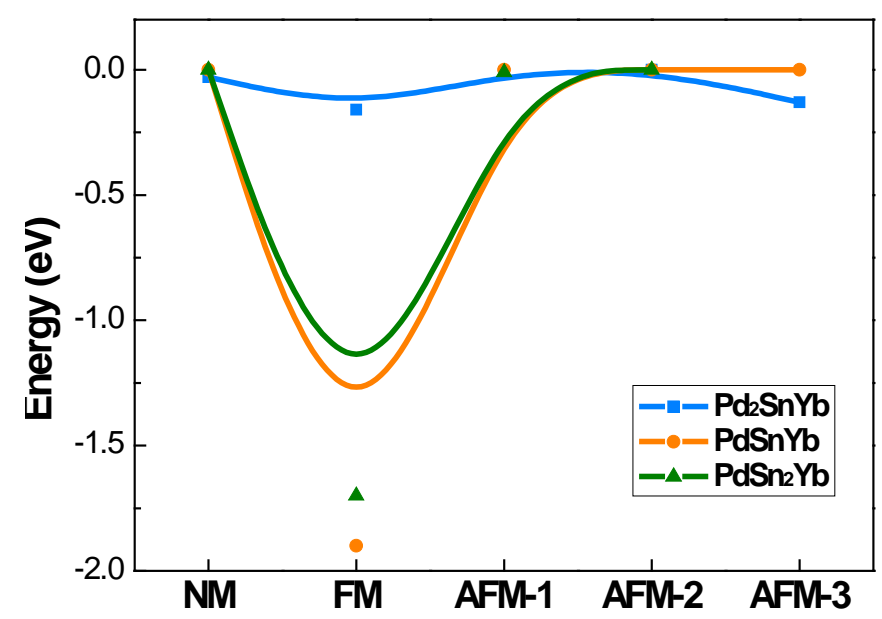

Figure 1. The energy curve of $\mathrm{NM}, \mathrm{FM}$ and $\mathrm{AFM}$ in $\mathrm{Pd}_{2} \mathrm{SnYb}$, $\mathrm{PdSnYb}$ and $\mathrm{PdSn} \mathrm{n}_{2} \mathrm{Yb}$. 
with the experiments [37] [38]. The calculated magnetic moment value of each $\mathrm{Yb}$ is $2.4 \mu_{\mathrm{B}}$ for the alloy composition $\mathrm{Pd}_{2} \mathrm{SnYb}$. The total magnetic moment of per formula unit for $\mathrm{Pd}_{2} \mathrm{SnYb}$ and atoms $\mathrm{Yb}, \mathrm{Pd}, \mathrm{Sn}$ are all $0 \mu_{\mathrm{B}}$. As we can see, $\mathrm{Pd}_{2} \mathrm{SnYb}$ is barely the magnetic one among the three Pd-based alloys. According to Mulliken's bond population and length shown in Table $1, \mathrm{Pd}_{2} \mathrm{SnYb}$ contains the bond type Pd-Yb, which the other two alloys don't. And the lack of Pd-Yb bonding maybe indicates the reason for appearing a transition from non-magnetism $\left(\mathrm{Pd}_{2} \mathrm{SnYb}, \mathrm{Pd}_{2} \mathrm{SnYb}\right)$ to anti-ferromagnetism $\left(\mathrm{Pd}_{2} \mathrm{SnYb}\right)$. The bond population means the distribution of overlapping electron charge between two atoms. It is usually used to evaluate the ionicity or covalency of a bond. Compared with the positive values of Pd-Sn, the negative of Pd-Yb displays its iconicity, which is also connected with the magnetism in $\mathrm{Pd}_{2} \mathrm{SnYb}$.

\subsection{Structural Parameters}

Based on the calculation of magnetic ground state in 3.1 Magnetic properties, lattice constant, volume, density, total energy, cohesive energy, formation enthalpy and partial experiment values of $\mathrm{Pd}_{2} \mathrm{SnYb}, \mathrm{PdSnYb}$ and $\mathrm{PdSn}_{2} \mathrm{Yb}$ are listed in Table 2. As we all know, GGA calculation usually overestimates lattice constants. On the contrary, the elastic constants are underestimated. Therefore, lattice parameters calculated by GGA are slightly larger. While the error is negligible, and the computed results still agree well with the experiment data.

For further details of the bonding properties in these alloys, the cohesive energy and formation enthalpy per atom of $\mathrm{Pd}, \mathrm{Sn}$ and $\mathrm{Yb}$ atoms are defined

Table 1. Mulliken's bond population and length (Á) of the Pd-based alloys.

\begin{tabular}{cccccccc}
\hline & \multicolumn{2}{c}{$\mathrm{Pd}_{2} \mathrm{SnYb}$} & \multicolumn{2}{c}{$\mathrm{PdSnYb}$} & \multicolumn{2}{c}{$\mathrm{PdSn}_{2} \mathrm{Yb}$} \\
\cline { 2 - 7 } & $\mathrm{Pd}-\mathrm{Sn}$ & $\mathrm{Pd}-\mathrm{Yb}$ & \multicolumn{3}{c}{$\mathrm{Pd}-\mathrm{Sn}$} & & $\mathrm{Pd}-\mathrm{Sn}$ \\
\hline population & 1.36 & -0.18 & 0.61 & 1.42 & 0.09 & 0.94 & 0.07 \\
length & 2.93 & 2.93 & 2.72 & 2.73 & 2.85 & 2.80 & 2.83 \\
\hline
\end{tabular}

Table 2. The calculated lattice constants $a, b, c(\AA)$, volume $V(\AA 3)$, density $\rho\left(\mathrm{g} \cdot \mathrm{cm}^{-3}\right)$, $E_{\text {tot }}(\mathrm{eV} /$ atom $), \Delta H(\mathrm{eV}), \Delta E_{c o h}(\mathrm{eV})$ and partial experiment values of $\mathrm{Pd}-\mathrm{Sn}-\mathrm{Yb}$.

\begin{tabular}{ccccccc}
\hline & $\mathrm{Pd}_{2} \mathrm{SnYb}$ & $\operatorname{Exp}[39]$ & $\mathrm{PdSnYb}$ & $\operatorname{Exp}[40]$ & $\mathrm{PdSn}_{2} \mathrm{Yb}$ & $\operatorname{Exp}[41]$ \\
\hline$S G$ & $F \overline{\mathbf{4} 3 \mathrm{~m}}$ & & $\mathrm{Pnma}$ & & $\mathrm{Cmcm}$ & \\
$a$ & 6.755 & 6.658 & 7.247 & 7.191 & 4.420 & 4.424 \\
$b$ & 6.755 & 6.658 & 4.638 & 4.588 & 11.059 & 11.086 \\
$c$ & 6.755 & 6.658 & 8.040 & 7.961 & 7.603 & 7.384 \\
$V$ & 308.264 & 295.142 & 270.231 & 262.652 & 371.627 & 362.144 \\
$\rho$ & 10.913 & 11.354 & 9.842 & 10.068 & 9.290 & 9.479 \\
$E_{\text {tot }}$ & -2022.47 & & -2430.19 & & -1846.57 & \\
$\Delta H$ & -0.844 & & -1.567 & & -2.750 & \\
$\Delta E_{\text {coh }}$ & -4.113 & & -4.986 & & -6.012 & \\
\hline
\end{tabular}


as the calculated Equation (1) and (2) [42] [43].

$$
\begin{gathered}
\Delta H=\frac{1}{x+y+z}\left(E_{\text {tot }}-x E_{\text {solid }}^{P d}-y E_{\text {solid }}^{S n}-z E_{\text {solid }}^{Y b}\right) \\
\Delta E_{\text {coh }}=\frac{1}{x+y+z}\left(E_{\text {tot }}-x E_{\text {atom }}^{P d}-y E_{\text {atom }}^{S n}-z E_{\text {atom }}^{Y b}\right)
\end{gathered}
$$

Here, $\Delta H$ and $\Delta E_{c o h}$ respectively represent the formation enthalpy and cohesive energy of Pd-based compounds. $E_{\text {tot }}$ stands for the energy of a unit cell. $E_{\text {solid }}^{P d}, E_{\text {solid }}^{S n}, E_{\text {solid }}^{Y b}$ are the energy of each $\mathrm{Pd}, \mathrm{Sn}$ and $\mathrm{Yb}$ atom in the bulk state, and $E_{\text {atom }}^{P d}, E_{\text {atom }}^{S n}, E_{\text {atom }}^{Y b}$ show the total energy of insular Pd, Sn, Yb atom, respectively. $x, y$ and $z$ are the number of $\mathrm{Pd}, \mathrm{Sn}$, and $\mathrm{Yb}$ atom in unit cell.

It is clear that the calculated formation enthalpy and the cohesive energy given in Table 2 are negative: $0>\mathrm{Pd}_{2} \mathrm{SnYb}>\mathrm{PdSnYb}>\mathrm{PdSn}_{2} \mathrm{Yb}$. The results show that $\mathrm{Pd}_{2} \mathrm{SnYb}, \mathrm{PdSnYb}$ and $\mathrm{PdSn}_{2} \mathrm{Yb}$ are all thermally stable. Among them, $\mathrm{PdSn}_{2} \mathrm{Yb}$ is the easiest to synthesis and the most stable alloy. And $\mathrm{Pd}_{2} \mathrm{SnYb}$, which has the poorest stability and reacts easily with $\mathrm{Cl}^{-}$or $\mathrm{H}^{+}$resulting in corrosion, is just on the contrary.

\subsection{Fermi Energy}

Fermi level $\left(E_{f}\right)$ also can be known as the Fermi energy. If the electrons accumulation in semiconductor is regarded as a thermodynamic system, the statistic theory has been proved that Fermi energy is the electronic chemical potential of this system.

$$
E_{f}=\mu=\left(\frac{\partial F}{\partial N}\right)_{T}
$$

in which $\mu$ is the chemical potential, $F$ is the free energy, $N$ represents the total number of electrons, $T$ is temperature.

The corrosion behavior on alloys is complicated. In the light of the electron theory, each fermion obeys Fermi-Dirac statistics. According to Pauli exclusionprinciple, the minimal energy principle, and Hund rule, fermion occupies the quantum state respectively. On behalf of the top level of electron filling, Fermi energy loses electron in the first. And the higher Fermi level reaches, the easier outermost shells are to lose.

Fermi energy of $\mathrm{Pd}_{2} \mathrm{SnYb}, \mathrm{PdSnYb}$, and $\mathrm{PdSn} n_{2} \mathrm{Yb}$ are shown in Figure 2. Due to the different types and structures of the system, Fermi level is different in the ground state. Corrosion potential is bound on with the Fermi level. So the higher Fermi level reaches, the smaller corrosion potential will be. As shown in Figure 2, the Fermi energy $\left(E_{f}\right)$ values of these compounds with $E_{f}(\mathrm{PdSnYb})>E_{f}$ $\left(\mathrm{Pd}_{2} \mathrm{SnYb}\right)>E_{f}\left(\mathrm{PdSn}_{2} \mathrm{Yb}\right)$ indicate that $\mathrm{PdSnYb}$ is most likely to lose electrons, while $\mathrm{PdSn} n_{2} \mathrm{Yb}$ is difficult. Their corrosion potential and complexity of corroding are in the order of $\mathrm{PdSn}_{2} \mathrm{Yb}>\mathrm{Pd}_{2} \mathrm{SnYb}>\mathrm{PdSnYb}$.

\subsection{Elastic Property}

The reaction to external stress in the elastic limit of crystal lattice can be charac- 


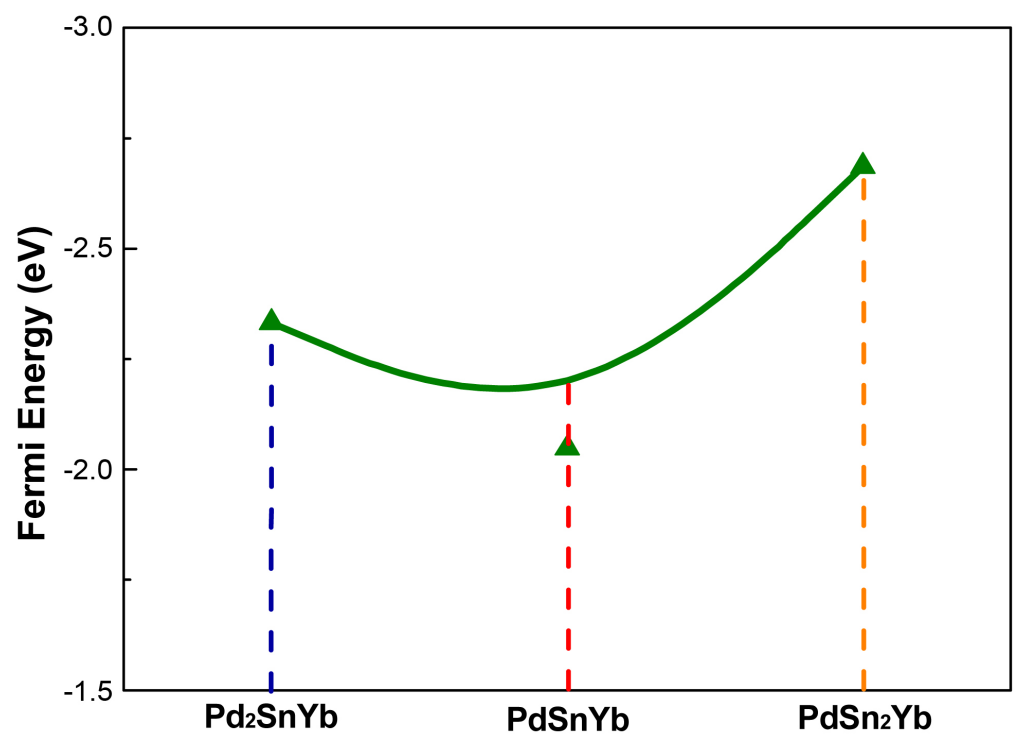

Figure 2. Fermi energy of $\mathrm{Pd}_{2} \mathrm{SnYb}, \mathrm{PdSnYb}$ and $\mathrm{PdSn}_{2} \mathrm{Yb}$.

terized by elastic constants. It's of important significant on the stability and stiffness of materials. Table 3 lists the elastic constants of these three alloys. The elastic constants of cubic and orthorhombic system need to satisfy the generalized stability criteria which can be expressed as [44]:

For cubic phase $\left(\mathrm{Pd}_{2} \mathrm{SnYb}\right)$ :

$$
\left(C_{11}+2 C_{12}\right)>0, C_{11}>\left|C_{12}\right|, C_{44}>0
$$

For orthorhombic phase $\left(\mathrm{PdSnYb}\right.$ and $\left.\mathrm{PdSn}_{2} \mathrm{Yb}\right)$ :

$$
\begin{aligned}
& C_{i j}>0,(i, j=1 \sim 6),\left[C_{11}+C_{22}+C_{33}+2\left(C_{12}+C_{13}+C_{23}\right)\right]>0 \\
& \left(C_{11}+C_{22}-2 C_{12}\right)>0,\left(C_{11}+C_{33}-2 C_{13}\right)>0,\left(C_{22}+C_{33}-2 C_{23}\right)>0
\end{aligned}
$$

As mentioned in Table 3, the mentioned Pd-based alloys are stable in mechanics, due to the elastic constants satisfy the corresponding stability criterions.

It's well known that the elastic constants $C_{11}$ and $C_{33}$ are depicted as the ability to resist linear compression along $x$ and $z$-axis [45]. The present $C_{11}$ is equal to $C_{33}$ in $\mathrm{Pd}_{2} \mathrm{SnYb}$, indicating that the compression of $x$ and $z$-axis is isotropy. The largest $C_{11}$ of $\mathrm{PdSnYb}$ implies that it is the most incompressible material along $x$-axes obviously. For $\mathrm{PdSn}_{2} \mathrm{Yb}$, the value of $C_{33}$ is slightly higher than the $C_{11}$, which indicates that the $z$-axis is less compressible than $X$-axis. The calculated elastic constants of $\mathrm{Pd}_{2} \mathrm{SnYb}$ follow the order: $C_{11}=C_{22}=C_{33}, C_{44}=C_{55}=C_{66}$, $C_{12}=C_{13}=C_{23}$, suggesting the anisotropies of shear moduli for Pd-based intermetallics are relatively weak. The PdSnYb is in the order of $C_{11}>C_{22}>C_{33}$. Thus, the bonding strength of adjacent atoms are the highest in ( $\left(\begin{array}{lll}1 & 0 & 0\end{array}\right)$ plane. The present $C_{22}$ is higher than the $C_{11}$ and $C_{22}$ for $\mathrm{PdSn}_{2} \mathrm{Yb}$. Therefore, the bonding strength of $\left(\begin{array}{lll}0 & 1 & 0\end{array}\right)$ plane is higher than $\left(\begin{array}{lll}1 & 0 & 0\end{array}\right)$ and $\left(\begin{array}{lll}0 & 0 & 1\end{array}\right)$ planes. In conclusion, all the three compounds have the highest binding strength in $\left(\begin{array}{lll}1 & 0 & 0\end{array}\right)$ plane.

Additionally, $C_{44}$, which measures the ability to resist monoclinic shear strain 
Table 3. Elastic constants (GPa) of the three Pd-Sn-Yb.

\begin{tabular}{|c|c|c|c|c|c|c|c|c|c|}
\hline & $C_{11}$ & $C_{22}$ & $C_{33}$ & $C_{44}$ & $C_{55}$ & $C_{66}$ & $C_{12}$ & $C_{13}$ & $C_{23}$ \\
\hline $\mathrm{Pd}_{2} \mathrm{SnYb}$ & 127 & 127 & 127 & 34 & 34 & 34 & 95 & 95 & 95 \\
\hline PdSnYb & 270 & 119 & 117 & 38 & 15 & 25 & 41 & 44 & 64 \\
\hline $\mathrm{PdSn} \mathrm{n}_{2} \mathrm{Yb}$ & 70 & 112 & 79 & 10 & 53 & 20 & 11 & 30 & 37 \\
\hline
\end{tabular}

in $\left(\begin{array}{lll}1 & 0 & 0\end{array}\right)$ plane, is a vital parameter indirectly affecting the indentation hardness [46]. The highest $C_{44}$ for $\mathrm{PdSnYb}$ indicates that it has the strongest resistance to shear deformation in $\left(\begin{array}{lll}1 & 0 & 0\end{array}\right)$ plane. The equation $\left(C_{12}-C_{44}\right)$ is a classical representation of Cauchy pressure. When the value of Cauchy pressure is positive, it reveals the material is ductile, whereas the negative value represents brittleness [47]. The computed Cauchy pressure for Pd-based intermetallics follows this order: PdSnYb $(232 \mathrm{GPa})>\mathrm{PdSn}_{2} \mathrm{Yb}(93 \mathrm{GPa})>\mathrm{PdSn}_{2} \mathrm{Yb}(60 \mathrm{GPa})>0$. The largest value of Cauchy pressure for $\mathrm{PdSnYb}$ and the smallest one for $\mathrm{PdSn}_{2} \mathrm{Yb}$ manifest $\mathrm{PdSnYb}$ is the most ductile structure and $\mathrm{PdSn}{ }_{2} \mathrm{Yb}$ is the least one.

For the polycrystalline system, elastic modulus can be got via independent elastic constants. In order to obtain the bulk modulus and shear modulus, we consult the Voigt and Reuss models. Ref. [44] sums up the expressions of bulk and shear modulus for different systems:

For cubic phase $\left(\mathrm{Pd}_{2} \mathrm{SnYb}\right)$ :

$$
\begin{gathered}
B_{V}=B_{R}=\left(C_{11}+2 C_{12}\right) / 3 \\
G_{V}=\left(C_{11}-C_{12}+3 C_{44}\right) / 5 \\
G_{R}=5\left(C_{11}-C_{12}\right) C_{44} /\left[4 C_{44}+3\left(C_{11}-C_{12}\right)\right]
\end{gathered}
$$

For orthorhombic phase $\left(\mathrm{PdSnYb}\right.$ and $\left.\mathrm{PdSn}_{2} \mathrm{Yb}\right)$ :

$$
\begin{gathered}
B_{V}=\frac{1}{9}\left[\left(C_{11}+C_{22}+C_{22}\right)+2\left(C_{12}+C_{13}+C_{23}\right)\right] \\
B_{V}=1 /\left[\left(S_{11}+S_{22}+S_{33}\right)+2\left(S_{12}+S_{13}+S_{23}\right)\right] \\
G_{V}=\frac{1}{15}\left[\left(C_{11}+C_{22}+C_{33}\right)-\left(C_{12}+C_{13}+C_{23}\right)+\left(C_{44}+C_{55}+C_{66}\right)\right] \\
G_{R}=15 /\left[4\left(S_{11}+S_{22}+S_{33}\right)-4\left(S_{12}+S_{13}+S_{23}\right)+3\left(S_{44}+S_{55}+S_{66}\right)\right]
\end{gathered}
$$

where $B_{V}, B_{R}$ and $G_{V}, G_{R}$, which represent the bulk modulus and shear modulus respectively, are calculated by Voigt and Reuss approximation.

According to the extreme value principle, the Reuss's and Voigt's models have been proved to be the lower and upper limits of the elastic constant by Hill [48]. The formula called Voigt-Reuss-Hill (VRH) agrees well with the experiments:

$$
\begin{aligned}
& B=\left(B_{V}+B_{R}\right) / 2 \\
& G=\left(G_{V}+G_{R}\right) / 2
\end{aligned}
$$

where $B$ and $G$ represent the bulk and shear modulus.

The value of bulk modulus and shear modulus, Young's modulus and Poisson's ratio using Hill's models are obtained: 


$$
\begin{gathered}
E=9 B G /(3 B+G) \\
v=(3 B-2 G) /[2(3 B+G)]
\end{gathered}
$$

Melting point, characterizing the thermodynamic stability of alloy, has always been considered as an important parameter. Deduced from Ref. [49], the melting temperature of materials, which is closely related to elastic constants, is estimated as follows:

$$
T_{m}=553+\left[5.91\left(C_{11}+C_{22}+C_{33}\right) / 3\right]-300
$$

Table 4 lists the elastic modulus (GPa), bulk modulus (GPa), shear modulus (GPa), Poisson's ratio $v$, Pugh modules ratio $G / B$ and the melting temperature $\left({ }^{\circ} \mathrm{C}\right)$ of $\mathrm{Pd}_{2} \mathrm{SnYb}, \mathrm{PdSnYb}$, and $\mathrm{PdSn}_{2} \mathrm{Yb}$.

Generally, the bulk modulus reflects the average values of bonding strength and the ability to resist volume change. Shear modulus measures the resistance to plastic deformation. As Table 4 shown, the bulk modulus is in the sequence of $\mathrm{Pd}_{2} \mathrm{SnYb}(106 \mathrm{GPa})>\mathrm{PdSnYb}(71 \mathrm{GPa})>\mathrm{PdSn} \mathrm{Yb}_{2}(45 \mathrm{GPa})$, indicating $\mathrm{Pd}_{2} \mathrm{SnYb}$ is the least compressible material in all structures. However, the shear moduli of them are almost the same. Young's modulus serves as a measure of the stiffness. The higher the Young's modulus is, the stiffer the material will be.

Poisson's ratio $v$ and Pugh modules ratio $G / B$ further confirm the brittleness and ductility of materials. Poisson's ratio $v$ reflects the elastic parameter of uniaxial deformation, especially in atom binding force. With 0.5 as the critical point, Poisson's ratio $v=0.5$ suggests the constancy of volume. When the variation of $v$ is between $0.25-0.5$, the atom binding force is central force. The $v$ value

Table 4. The calculated values for elastic modulus (GPa), bulk modulus (GPa), shear modulus (GPa), Poisson's ratio and Pugh modules ratio $G / B$, melting temperature $T_{m}$ $\left({ }^{\circ} \mathrm{C}\right)$.

\begin{tabular}{cccc}
\hline & $\mathrm{Pd}_{2} \mathrm{SnYb}$ & $\mathrm{PdSnYb}$ & $\mathrm{PdSn}_{2} \mathrm{Yb}$ \\
\hline$E(\mathrm{GPa})$ & 70 & 72 & 63 \\
$E[100](\mathrm{GPa})$ & 47 & 90 & 59 \\
$E[010](\mathrm{GPa})$ & 47 & 82 & 95 \\
$E[001](\mathrm{GPa})$ & 47 & 78 & 57 \\
$B(\mathrm{GPa})$ & 106 & 71 & 45 \\
$G(\mathrm{GPa})$ & 25 & 27 & 25 \\
$v_{x y}$ & 0.426 & 0.198 & -0.030 \\
$v_{y x}$ & 0.426 & 0.181 & -0.049 \\
$v_{z x}$ & 0.426 & 0.234 & 0.379 \\
$v_{x z}$ & 0.426 & 0.270 & 0.387 \\
$v_{y z}$ & 0.426 & 0.478 & 0.483 \\
$v_{z y}$ & 0.426 & 0.455 & 0.291 \\
$v$ & 0.390 & 0.330 & 0.267 \\
$G / B$ & 0.238 & 0.383 & 0.551 \\
$T_{m}\left({ }^{\circ} \mathrm{C}\right)$ & 984 & 1230 & 747 \\
\hline
\end{tabular}


for $\mathrm{Pd}_{2} \mathrm{SnYb}, \mathrm{PdSnYb}$ and $\mathrm{PdSn}{ }_{2} \mathrm{Yb}$ is higher than 0.25 , which shows the atomic forces are remarkably central forces. $\mathrm{Pd}_{2} \mathrm{SnYb}$ presents the largest $v$, reflecting its resistance of shear strain is the weakest. In accordance with Pugh's criterion [50], material with $G / B>0.57$ is brittle; whereas material with $G / B<0.57$ shows ductility. In Table 4, the G/B ratios of $\mathrm{Pd}_{2} \mathrm{SnYb}, \mathrm{PdSnYb}$, and $\mathrm{PdSn}_{2} \mathrm{Yb}$ are less than 0.57 . Thus, these three alloys are deemed to be ductility. The melting point of alloys is implied its thermodynamic stability. In Table 4 the melting temperature of $\mathrm{Pd}_{2} \mathrm{SnYb}, \mathrm{PdSnYb}$, and $\mathrm{PdSn}_{2} \mathrm{Yb}$ are $984^{\circ} \mathrm{C}, 1230^{\circ} \mathrm{C}, 747^{\circ} \mathrm{C}$, respectively, which further verifies the stability.

\subsection{Anisotropy}

\subsubsection{Elastic Anisotropy}

It is well known that single crystal is anisotropic, which has great influence on the performance of thin-film materials. So how to characterize the degree of anisotropic is necessary. To obtain the anisotropic degree of Pd-based alloys, the two-dimensional images of shear modulus of $\mathrm{Pd}_{2} \mathrm{SnYb}, \mathrm{PdSnYb}$, and $\mathrm{PdSn}{ }_{2} \mathrm{Yb}$ are described in Figure 3, the two quarter circles with radius of 50 and 100 in

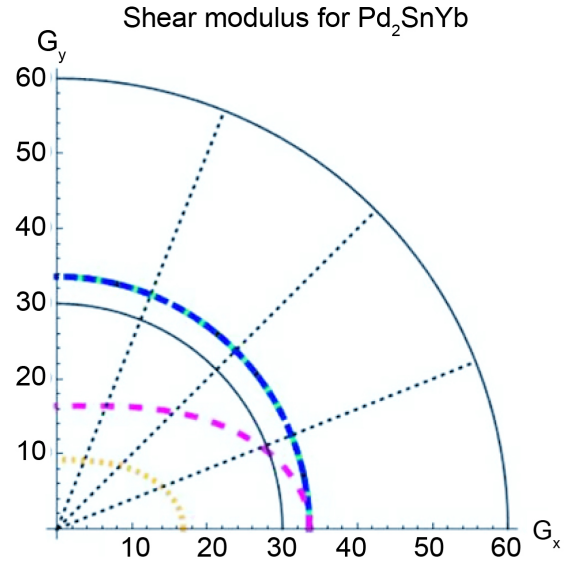

(a)

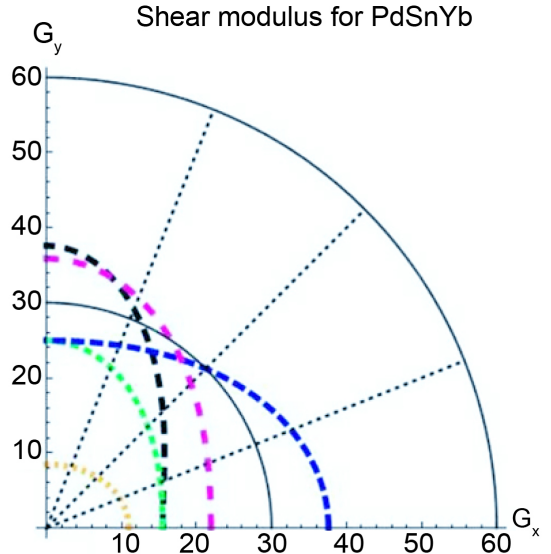

(b)

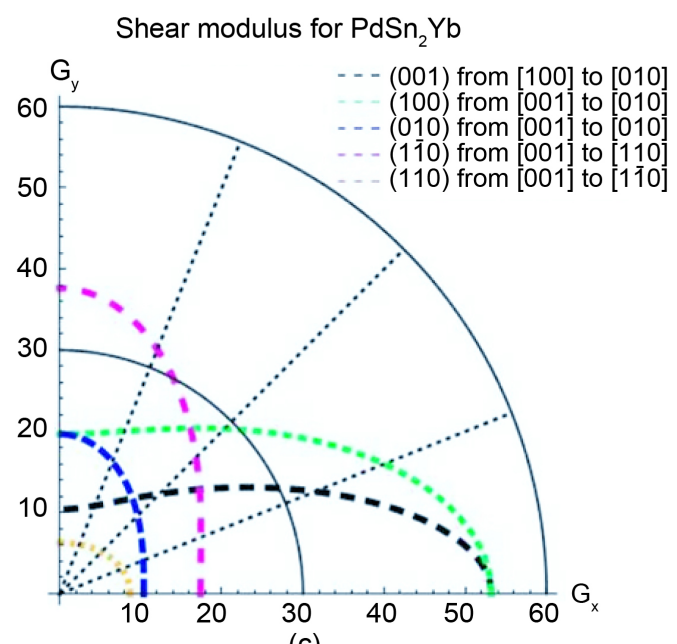

(c)

Figure 3. Two-dimensional graphs of the shear modulus (GPa) in Pd-Sn-Yb alloys. (a) $\mathrm{Pd}_{2} \mathrm{SnYb},(\mathrm{b}) \mathrm{PdYbSn},(\mathrm{c}) \mathrm{YbSn}_{2} \mathrm{Yb}$. 
Figure 3, which are labeled in black solid line, mean isotropy and play a supporting role in estimating the anisotropic degree.

The share modulus $G$ on different plane along different directions can be expressed as [51]:

(001) plane from [100] to [010]: $G^{-1}=\sin ^{2} \theta \cdot S_{44}+\cos ^{2} \theta \cdot S_{55}$

(100) plane from [100] to [010]: $G^{-1}=\sin ^{2} \theta \cdot S_{66}+\cos ^{2} \theta \cdot S_{55}$

(010) plane from [100] to [010]: $G^{-1}=\sin ^{2} \theta \cdot S_{66}+\cos ^{2} \theta \cdot S_{44}$

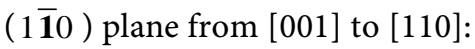

$$
G^{-1}=\sin ^{2} \theta \cdot S_{11}-2 \sin ^{2} \theta \cdot S_{12}+\sin ^{2} \theta \cdot S_{22}+\frac{1}{2} \cos ^{2} \theta \cdot S_{44}+\frac{1}{2} \cos ^{2} \theta \cdot S_{55}
$$

(110) plane from [001] to [1 $\overline{\mathbf{1}} 0]$ :

$$
\begin{aligned}
G^{-1}= & 2 \sin ^{2} \theta \cdot S_{11}+4 \sin ^{2} \theta \cdot S_{12}+2 \sin ^{2} \theta \cdot S_{22}+\cos ^{2} \theta \cdot S_{44} \\
& +\cos ^{2} \theta \cdot S_{55}+2 \cos ^{2} \theta \cdot S_{66}
\end{aligned}
$$

in which $\theta$ represent the angle between [ $u v w$ ] direction and [HKL] direction.

As we can see in Figure 3(a), the shear modulus of $\mathrm{Pd}_{2} \mathrm{SnYb}$ in (001), (100), and (010) trajectory planes are similar to the quarter circles, which imply that $\mathrm{Pd}_{2} \mathrm{SnYb}$ shows almost isotropy in these planes. On the curves of (110 ) plane from [001] to [110] and (110) plane from [001] to [1 $\overline{10}$ ], shear modulus show obviously anisotropy of $\mathrm{Pd}_{2} \mathrm{SnYb}$. For $\mathrm{PdSnYb}$ and $\mathrm{PdSn} \mathrm{n}_{2} \mathrm{Yb}$, shear modulus are all anisotropy due to the noncircular plots on the mentioned planes along different directions. To take a panoramic view of Figure 3, shear modulus is the smallest on (110) plane, which suggests it may be the glide plane of Pd-based alloys.

In order to clearly illustrate the anisotropies of mechanical modulus for $\mathrm{Pd}_{2} \mathrm{SnYb}, \mathrm{PdSnYb}$, and $\mathrm{PdSn}_{2} \mathrm{Yb}$, we plot three dimensional surfaces of modulus in Figure 4. For bulk modulus and Young's modulus, the 3D plots can be more intuitive to determine the ability to withstand external stress. Their formulas are as follow:

bulk modulus [52]:

$$
\begin{aligned}
B^{-1}= & 3\left[\left(S_{11}+S_{12}+S_{13}\right) l_{1}^{2}+\left(S_{16}+S_{26}+S_{36}\right) l_{1} l_{2}+\left(S_{12}+S_{22}+S_{23}\right) l_{2}^{2}\right. \\
& \left.+\left(S_{14}+S_{24}+S_{34}\right) l_{2} l_{3}+\left(S_{13}+S_{23}+S_{33}\right) l_{3}^{2}+\left(S_{15}+S_{25}+S_{35}\right) l_{1} l_{3}\right]
\end{aligned}
$$

Young's modulus [53]:

$$
E^{-1}=S_{1111}^{\prime}=\sum_{n=1}^{3} \sum_{m=1}^{3} \sum_{p=1}^{3} \sum_{q=1}^{3} S_{n m p q} l_{1 n} l_{1 m} l_{1 p} l_{1 q}
$$

where $S_{\text {nmpq }}$ is the elastic compliance coefficient and $l_{1 n}, l_{1 m}, l_{1 p}, l_{1 q}$ represent the directional cosine.

In Figure 4, the bulk modulus of $\mathrm{Pd}_{2} \mathrm{SnYb}$ is spherical, reflecting isotropy of the bulk modulus. The three dimensional graphs of bulk modulus of PdSnYb and $\mathrm{PdSn} \mathrm{n}_{2} \mathrm{Yb}$, and Young's modulus of $\mathrm{Pd}_{2} \mathrm{SnYb}$ are irregularly. Thus, they express anisotropic nature, as well as the $\mathrm{PdSn} \mathrm{S}_{2} \mathrm{Yb}$ performs the strongest anisotropy. Conversely, $\mathrm{Pd}_{2} \mathrm{SnYb}$ is isotropy, which is in good agreement with the 


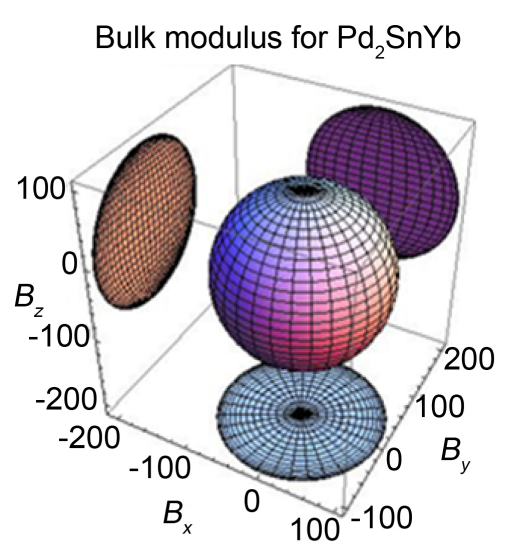

Young's modulus for $\mathrm{Pd}_{2} \mathrm{SnYb}$

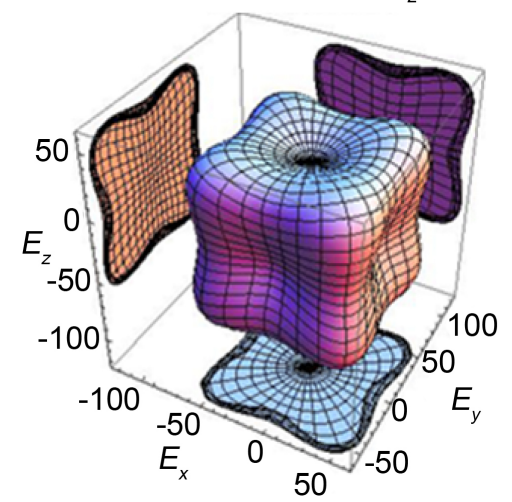

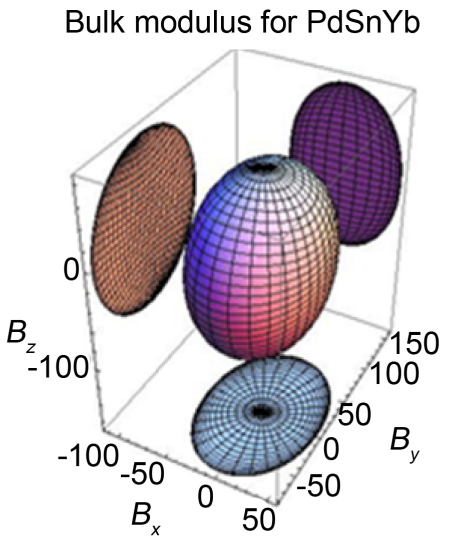

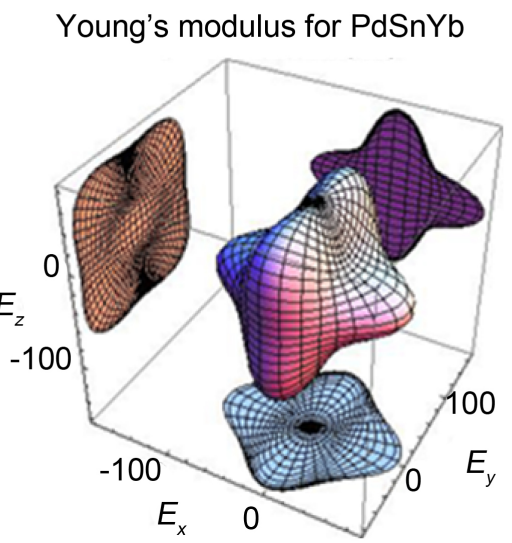

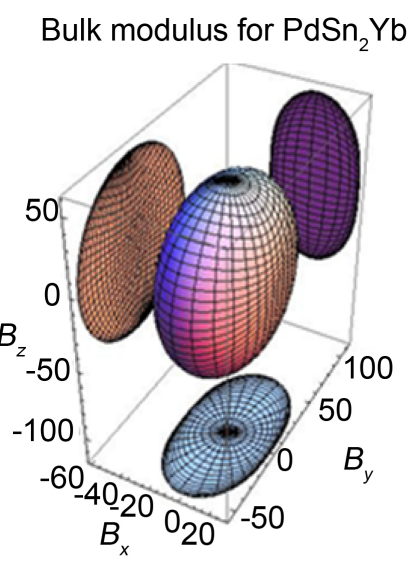

Young's modulus for $\mathrm{PdSn}_{2} \mathrm{Yb}$

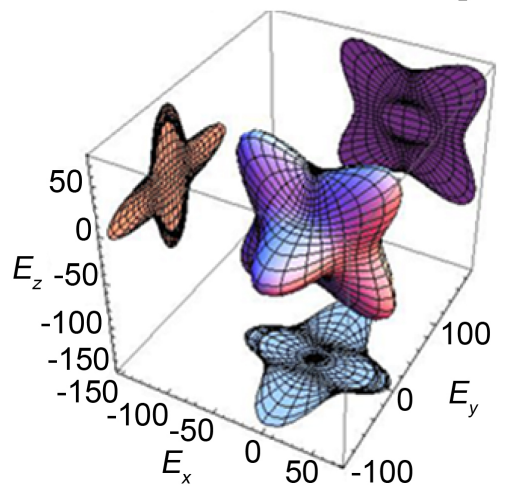

Figure 4. Three-dimensional stereograms of the bulk modulus and Young's modulus (GPa) of Pd-Sn-Yb.

calculated anisotropy of shear modulus in the present work. Compared with bulk modulus, the projections of Young's modulus on the (100), (010) and (001) planes show a more pronounced anisotropy. Therefore, a stronger directional dependence of Young's modulus has displayed on these planes.

\subsubsection{Ideal Strength of Tensile and Shear Deformation}

It is essential to comprehend the causation of the structural stability for the design and application of these Pd-based alloys, especially the response of lattice stress to the applied strain. To analysis the mechanism of mechanical deformation, the stress-strain curves of tensile and shear deformation are performed in Figure 5.

For tensile deformation, the strain directions [100], [010], [001] are parallel to the coordinate axis of the corresponding unit cell. From Figures 5(a)-(c), the tensile strengths of $\mathrm{PdSnYb}$ and $\mathrm{PdSn}_{2} \mathrm{Yb}$ show anisotropy. And the strongest ideal tensile strengths of these two alloys exist in the strain direction [001]. Due to the different symmetry of $\mathrm{Pd}_{2} \mathrm{SnYb}$ compared with $\mathrm{PdSnYb}$ and $\mathrm{PdSn}{ }_{2} \mathrm{Yb}$, it's isotropic along the strain direction [100], [010], and [001]. The yielding stage of $\mathrm{Pd}_{2} \mathrm{SnYb}, \mathrm{PdSnYb}$, and $\mathrm{PdSn}_{2} \mathrm{Yb}$ in different orientations all occurs in $2 \%$ strains.

It can be seen in the Figures 5(d)-(f) that the shear moduli can be obtained from the strains less than $2 \%$ [54]. On the basis of this linear parts, the computed 

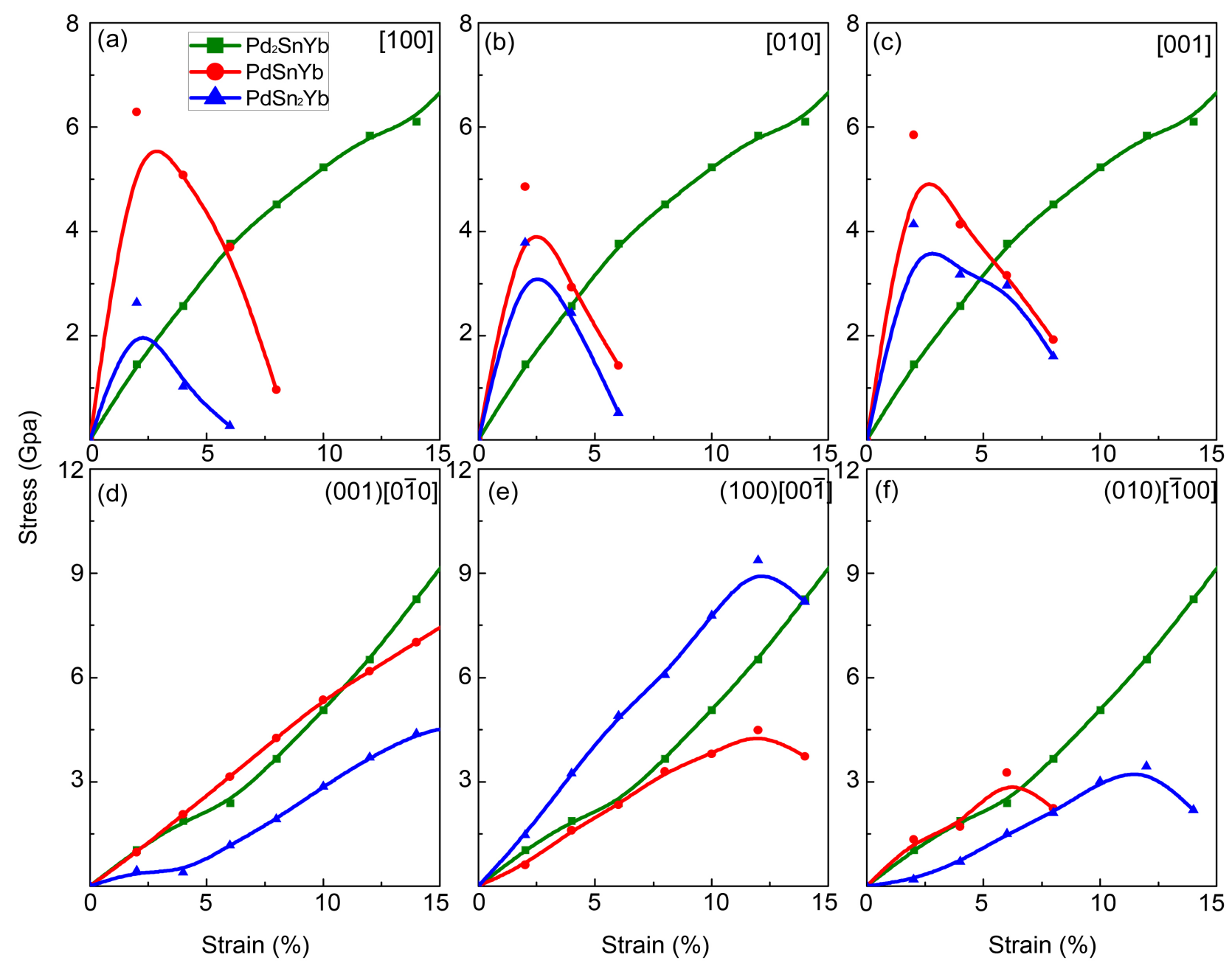

Figure 5. The tensile and shear stress-strain curves of Pd-based alloys along different directions.

shear moduli values are

$\mathrm{G}(100)[0 \overline{\mathbf{1}} 0]=\mathrm{G}(010)[00 \overline{\mathbf{1}}]=\mathrm{G}(001)[\overline{\mathbf{1}} 00]=52 \mathrm{GPa}$ for $\mathrm{Pd}_{2} \mathrm{SnYb}$,

$G(100)[\overline{\mathbf{1}} 00]=48.5 \mathrm{GPa}, G(010)[00 \overline{\mathbf{1}}]=30.5 \mathrm{GPa}, \quad G(001)[\overline{\mathbf{1}} 00]=67 \mathrm{GPa}$ for PdSnYb and $G(100)[0 \overline{\mathbf{1}} 0]=21.5 \mathrm{GPa}, G(010)[00 \overline{\mathbf{1}}]=73 \mathrm{GPa}$,

$G(001)[\overline{\mathbf{1}} 00]=9 \mathrm{GPa}$ for $\mathrm{PdSn}_{2} \mathrm{Yb}$, respectively. In contrast with the results using Voigt-Reuss-Hill method, they are not accord, which proves that they are all anisotropic in the whole crystal of the three structures.

\subsection{The Minimum Value of Thermal Conductivity $\boldsymbol{K}_{\min }$}

The thermal conductivity is a measure of material's heat conduction ability. Therefore, the research on it of Pd-based alloys in this work is significant.

Owing to the lattice vibration influences the crystal macroscopic thermodynamic properties, the lattice vibration becomes important factors we want to know. And lattice vibration is determined by phonon system. Thus it has great significance to the materials' thermal conductivity. The transverse acoustic wave velocity $\left(v_{t}\right)$, longitudinal acoustic wave velocity $\left(v_{l}\right)$, and wave velocity $\left(v_{m}\right)$ are calculated [55]: 


$$
\begin{gathered}
v_{t}=\sqrt{G / \rho} \\
v_{l}=\sqrt{(B+4 G / 3) / \rho} \\
v_{m}=\frac{1}{3}\left(2 / v_{t}^{3}+1 / v_{l}^{3}\right)^{-1 / 3}
\end{gathered}
$$

In the condition of high temperature, the value of thermal conductivity will decrease with increasing temperature [56]. Hence the minimum thermal conductivity value for materials in the applications of high temperature is extremely important. The minimum thermal conductivity of $\mathrm{Pd}_{2} \mathrm{SnYb}, \mathrm{PdSnYb}$, and $\mathrm{PdSn}_{2} \mathrm{Yb}$ is calculated on the basis of Clark's model [56] and Cahill's model [57]:

$$
\begin{aligned}
& \text { Clark's Model: } K_{\min }=0.87 k_{B} M_{a}^{-2 / 3} E^{1 / 2} \rho^{1 / 6} \\
& \text { Cahill's Model: } K_{\min }=\left(k_{B} / 2.48\right) \rho^{2 / 3}\left(v_{1}+v_{2}+v_{3}\right)
\end{aligned}
$$

where $k_{B}$ represents Boltzmann's constant, $\mathrm{Ma}$ is the average mass of atoms, $E$ is the Young's modulus, $\rho$ is density, $v_{n}(n=1,2,3)$ is acoustic wave velocity, $p$ is the number of atoms in unit volume. All the indexes are calculated in Table 5. The thermal conductivity for cubic $\mathrm{ZrO}_{2}$ is also calculated, aiming to compare the value with the experimental value to confirm the accuracy of the calculation method.

As shown in Table 5, the calculated thermal conductivity using the Cahill's model is lightly greater than that computed by the Clark's model. This is due to the atom number density and phonon spectrum are both considered in Cahill's model, whereas the Clark's model does not [58]. Thus, the Clark's model underestimates the thermal conductivity, however the value adopting Cahill's model gets closer to the real values of thermal conductivity. In comparison with Clark's model, the Cahill's value of $\mathrm{ZrO}_{2}$ is closer to the experimental value, which confirms this calculation method is credible. As for $\mathrm{Pd}_{2} \mathrm{SnYb}$, the minimum thermal conductivity is largest, and that for $\mathrm{PdSn}_{2} \mathrm{Yb}$ is the smallest. Compared to the results in the present work, the increasing content of Sn atoms cause the decreasing in minimum thermal conductivity, when the proportion of $\mathrm{Pd} / \mathrm{Sn}$ ratios modify. As is known to all, the $\mathrm{Y}_{2} \mathrm{O}_{3}$-stabilized $\mathrm{ZrO}_{2}\left(\sim 2.2 \mathrm{~W} \cdot \mathrm{m}^{-1} \cdot \mathrm{K}^{-1}\right)$ are investigated for application as materials for thermal barrier coatings. Based on the accuracy of the calculation method, the calculated minimum thermal conductivities of $\mathrm{Pd}_{2} \mathrm{SnYb}, \mathrm{PdSnYb}$ and $\mathrm{PdSn}_{2} \mathrm{Yb}$ are all at least a quarter less than $\mathrm{ZrO}_{2}$,

Table 5. Transverse speed $v_{t}\left(\mathrm{~km} \cdot \mathrm{s}^{-1}\right)$, longitudinal speed $v_{1}\left(\mathrm{~km} \cdot \mathrm{s}^{-1}\right)$, acoustic speed $v_{\mathrm{m}}$ $\left(\mathrm{km} \cdot \mathrm{s}^{-1}\right)$ for $\mathrm{Pd}-\mathrm{Sn}-\mathrm{Yb}$, and the minimum thermal conductivities $K_{\min }\left(\mathrm{W} \cdot \mathrm{m}^{-1} \cdot \mathrm{K}^{-1}\right)$ of Cahill's Model, Clark's Model for Pd-Sn-Yb and $\mathrm{ZrO}_{2}$.

\begin{tabular}{ccccccc}
\hline & $V_{t}$ & $V_{l}$ & $V_{m}$ & Chill & Clark & \multirow{2}{*}{$K_{\min }^{\text {exp }}$} \\
\hline $\mathrm{Pd}_{2} \mathrm{SnYb}$ & 1519 & 3572 & 1717 & 0.53 & 0.42 & \\
$\mathrm{PdSnYb}$ & 1163 & 3304 & 1865 & 0.48 & 0.41 & \\
$\mathrm{PdSn}_{2} \mathrm{Yb}$ & 1635 & 2902 & 1819 & 0.43 & 0.39 & \\
$\mathrm{ZrO}_{2}$ & 4188 & 7774 & 4675 & 1.86 & 1.62 & $2.2[59]$ \\
\hline
\end{tabular}


which show $\mathrm{Pd}_{2} \mathrm{SnYb}, \mathrm{PdSnYb}$ and $\mathrm{PdSn}_{2} \mathrm{Yb}$ can be used for high-temperatureresistant materials, aerospace field, and many other fields.

\section{Conclusions}

The calculated results showed that the AFM-2 state of $\mathrm{Pd}_{2} \mathrm{SnYb}$ and the NM state of $\mathrm{PdSnYb}, \mathrm{PdSn}_{2} \mathrm{Yb}$ are found to be the ground state, which are agreed with experimental reports. The obtained enthalpy of formation and binding energy are in the order: $0>\mathrm{Pd}_{2} \mathrm{SnYb}>\mathrm{PdSnYb}>\mathrm{PdSn}_{2} \mathrm{Yb}$, indicating that the Pd-based alloys are mechanically stable. The Fermi energy $\left(E_{f}\right)$ values of these compounds with $E_{f}(\mathrm{PdSnYb})>E_{f}\left(\mathrm{Pd}_{2} \mathrm{SnYb}\right)>E_{f}\left(\mathrm{PdSn}_{2} \mathrm{Yb}\right)$ imply that $\mathrm{PdSnYb}$ is most likely to lose electrons while $\mathrm{PdSn}_{2} \mathrm{Yb}$ is difficult. In line with the Cauchy pressure, values of Poisson's ratio $v$, and Pugh modules ratio $G / B$, these three alloys are deemed to be ductility. The three compounds are all elastic anisotropic, and the anisotropic sequence is $\mathrm{PdSn}_{2} \mathrm{Yb}>\mathrm{PdSnYb}>\mathrm{Pd}_{2} \mathrm{SnYb}$. The ideal strength of tensile and shear deformation are inconformity in different crystal orientations, implying that $\mathrm{Pd}_{2} \mathrm{SnYb}, \mathrm{Pd}_{2} \mathrm{SnYb}$, and $\mathrm{Pd}_{2} \mathrm{SnYb}$ are plastic anisotropic. Moreover, the calculated minimum thermal conductivities of $\mathrm{Pd}_{2} \mathrm{SnYb}$, $\mathrm{PdSnYb}$ and $\mathrm{PdSn}_{2} \mathrm{Yb}$ are all at least a quarter less than that of $\mathrm{ZrO}_{2}$, the usual thermal barrier coatings materials. That implies these Pd-based alloys can be candidates for high-temperature-resistant materials.

\section{Acknowledgements}

This work was supported by Fundamental Research Funds for the Central Universities (XDJK2016D043).

\section{References}

[1] Felser, C., Fecher, G.H. and Balke, B. (2007) Spintronics: A Challenge for Materials Science and Solid-State Chemistry. Angewandte Chemie International Edition, 46, 668-699.http://dx.doi.org/10.1002/anie.200601815

[2] Barth, J., Fecher, G.H., Balke, B., Graf, T., Shkabko, A., Weidenkaff, A. and Ueda, S. (2011) Anomalous Transport Properties of the Half-Metallic Ferromagnets $\mathrm{Co}_{2} \mathrm{TiSi}$, $\mathrm{Co}_{2}$ TiGe and $\mathrm{Co}_{2}$ TiSn. Philosophical Transactions of the Royal Society of London A: Mathematical, Physical and Engineering Sciences, 369, 3588-3601.

http://dx.doi.org/10.1098/rsta.2011.0183

[3] Sharma, V., Solanki, A.K. and Kashyap, A. (2010) Electronic, Magnetic and Transport Properties of $\mathrm{Co}_{2} \mathrm{TiZ}(\mathrm{Z}=\mathrm{Si}, \mathrm{Ge}$ and $\mathrm{Sn})$ : A First-Principle Study. Journal of Magnetism and Magnetic Materials, 322, 2922-2928. http://dx.doi.org/10.1016/j.jmmm.2010.05.006

[4] Pierre, J., Skolozdra, R.V., Gorelenko, Y.K. and Kouacou, M. (1994) From Nonmagnetic Semiconductor to Itinerant Ferromagnet in the TiNiSn-TiCoSn Series. Journal of Magnetism and Magnetic Materials, 134, 95-105. http://dx.doi.org/10.1016/0304-8853(94)90078-7

[5] Wang, L.L., Miao, L., Wang, Z.Y., Wei, W., Xiong, R., Liu, H.J. and Tang, X.F. (2009) Thermoelectric Performance of Half-Heusler Compounds TiNiSn and TiCoSb. Journal of Applied Physics, 105, Article ID: 013709. http://dx.doi.org/10.1063/1.3056384 
[6] Raphael, M.P., Ravel, B., Huang, Q., Willard, M.A., Cheng, S.F., Das, B.N. and Harris, V.G. (2002) Presence of Antisite Disorder and Its Characterization in the Predicted Half-Metal $\mathrm{Co}_{2} \mathrm{MnSi}$. Physical Review B, 66, Article ID: 104429. https://doi.org/10.1103/PhysRevB.66.104429

[7] Umetsu, R.Y., Kobayashi, K., Kainuma, R., Fujita, A., Fukamichi, K., Ishida, K. and Sakuma, A. (2004) Magnetic Properties and Band Structures of Half-Metal-Type $\mathrm{Co}_{2} \mathrm{Cr} \mathrm{Ga}$ Heusler Alloy. Applied physics letters, 85, 2011-2013. http://dx.doi.org/10.1063/1.1790029

[8] Stanley, H.B., Lynn, J.W., Shelton, R.N. and Klavins, P. (1987) Antiferromagnetic Structure of the Cubic Superconductor $\mathrm{ErPd}_{2} \mathrm{Sn}$. Journal of Applied Physics, 61, 3371-3373. http://dx.doi.org/10.1063/1.338775

[9] Dönni, A., Fischer, P., Fauth, F., Convert, P., Aoki, Y., Sugawara, H. and Sato, H. (1999) Antiferromagnetic Ordering in the Cubic Superconductor $\mathrm{YbPd}_{2} \mathrm{Sn}$. Physica B: Condensed Matter, 259, 705-706. http://dx.doi.org/10.1016/S0921-4526(98)01081-3

[10] Jeong, T. and Kwon, Y. (2007). Ab-Initio Studies on the Electronic Structure of Y $\mathrm{bPd}_{2}$ Sn. Solid State Communications, 143, 429-431. http://dx.doi.org/10.1016/j.ssc.2007.06.008

[11] Heusler, F. (1904) Über Manganbronze und über die Synthese magnetisierbarer Legierungen aus unmagnetischen Metallen. Angewandte Chemie, 17, 260-264. https://doi.org/10.1002/ange.19040170903

[12] Webster, P.J. (1969) Heusler Alloys. Contemporary Physics, 10, 559-577. https://doi.org/10.1080/00107516908204800

[13] Liu, G.D., Dai, X.F., Yu, S.Y., Zhu, Z.Y., Chen, J.L., Wu, G.H., Xiao, J.Q., et al. (2006) Physical and Electronic Structure and Magnetism of $\mathrm{Mn}_{2} \mathrm{NiGa}$ : Experiment and Density-Functional Theory Calculations. Physical Review B, 74, Article ID: 054435. https://doi.org/10.1103/PhysRevB.74.054435

[14] Weht, R. and Pickett, W.E. (1999) Half-Metallic Ferrimagnetism in $\mathrm{Mn}_{2}$ VAl. Physical Review B, 60, Article ID: 13006. https://doi.org/10.1103/PhysRevB.60.13006

[15] Özdogan, K., Galanakis, I., Şaşioglu, E. and Aktaş, B. (2006) Search for Half-Metallic Ferrimagnetism in V-Based Heusler Alloys $\mathrm{Mn}_{2} \mathrm{VZ}(\mathrm{Z}=\mathrm{Al}, \mathrm{Ga}, \mathrm{In}, \mathrm{Si}, \mathrm{Ge}, \mathrm{Sn})$. Journal of Physics. Condensed Matter, 18, 2905. https://doi.org/10.1088/0953-8984/18/10/013

[16] Xing, N., Li, H., Dong, J., Long, R. and Zhang, C. (2008) First-Principle Prediction of Half-Metallic Ferrimagnetism of the Heusler Alloys $\mathrm{Mn}_{2} \mathrm{CoZ}(\mathrm{Z}=\mathrm{Al}, \mathrm{Ga}, \mathrm{Si}, \mathrm{Ge})$ with a High-Ordered Structure. Computational Materials Science, 42, 600-605. https://doi.org/10.1016/j.commatsci.2007.09.007

[17] Ishida, S., Akazawa, S., Kubo, Y. and Ishida, J. (1982) Band Theory of $\mathrm{Co}_{2} \mathrm{MnSn}$, $\mathrm{Co}_{2}$ TiSn and $\mathrm{Co}_{2}$ TiAl. Journal of Physics F: Metal Physics, 12, 1111. https://doi.org/10.1088/0305-4608/12/6/012

[18] Barth, J., Fecher, G.H., Balke, B., Ouardi, S., Graf, T., Felser, C., Yoshikawa, H., et al. (2010) Itinerant Half-Metallic Ferromagnets $\mathrm{Co}_{2} \mathrm{Ti} Z(Z=\mathrm{Si}, \mathrm{Ge}, \mathrm{Sn})$ : Ab Initio Calculations and Measurement of the Electronic Structure and Transport Properties. Physical Review B, 81, Article ID: 064404. https://doi.org/10.1103/PhysRevB.81.064404

[19] Sprungmann, D., Westerholt, K., Zabel, H., Weides, M. and Kohlstedt, H. (2010) Evidence for Triplet Superconductivity in Josephson Junctions with Barriers of the Ferromagnetic Heusler Alloy $\mathrm{Cu}_{2} \mathrm{MnAl}$. Physical Review B, 82, Article ID: 060505. https://doi.org/10.1103/PhysRevB.82.060505

[20] Baek, K.H., Kim, J.H., Woo, H.J., Lee, G.J., Lee, Y.P. and Yoon, C.S. (2009) Magnet- 
ic Grating Produced by Localized Crystallization of Amorphous $\mathrm{Cu}_{2} \mathrm{MnSn}$ Thin Film Using Femtosecond Laser Pulses. Journal of Applied Physics, 105, Article ID: 083927. https://doi.org/10.1063/1.3103582

[21] Ko, V., Han, G., Qiu, J. and Feng, Y.P. (2009) The Band Structure-Matched and Highly Spin-Polarized $\mathrm{Co}_{2} \mathrm{CrZ} / \mathrm{Cu}_{2} \mathrm{CrAl}$ Heusler Alloys Interface. Applied Physics Letters, 95, Article ID: 202502. https://doi.org/10.1063/1.3263952

[22] Simon, E., Vida, J.G., Khmelevskyi, S. and Szunyogh, L. (2015) Magnetism of Ordered and Disordered $\mathrm{Ni}_{2} \mathrm{MnAl}$ Full Heusler Compounds. Physical Review B, 92, Article ID: 054438. https://doi.org/10.1103/PhysRevB.92.054438

[23] Galanakis, I. and Şaşığlu, E. (2011) Structural-Induced Antiferromagnetism in Mn-Based Full Heusler Alloys: The Case of $\mathrm{Ni}_{2} \mathrm{MnAl}$. Applied Physics Letters, 98 , Article ID: 102514. https://doi.org/10.1063/1.3565246

[24] Kierstead, H.A., Dunlap, B.D., Malik, S.K., Umarji, A.M. and Shenoy, A.G. (1985) Coexistence of Ordered Magnetism and Superconductivity in $\mathrm{Pd}_{2} \mathrm{YbSn}$. Physical Review B, 32, 135. https://doi.org/10.1103/PhysRevB.32.135

[25] Aoki, Y., Sato, H.R., Matsuda, T.D., Sugawara, H. and Sato, H. (1998) Coexistence of and Competition between, Superconductivity and Magnetism in $\mathrm{YbPd}_{2} \mathrm{Sn}$. Journal of Magnetism and Magnetic Materials, 177, 559-560. https://doi.org/10.1016/S0304-8853(97)00385-5

[26] Aoki, Y., Sato, H.R., Sugawara, H. and Sato, H. (2000) Anomalous Magnetic Properties of Heusler Superconductor $\mathrm{YbPd}_{2} \mathrm{Sn}$. Physica C: Superconductivity, 333, $187-$ 194. https://doi.org/10.1016/S0921-4534(00)00100-3

[27] Wernick, J.H., Hull, G.W., Geballe, T.H., Bernardini, J.E. and Waszczak, J.V. (1983) Superconductivity in Ternary Heusler Intermetallic Compounds. Materials Letters, 2, 90-92. https://doi.org/10.1016/0167-577X(83)90043-5

[28] Hohenberg, P. and Kohn, W. (1964) Inhomogeneous Electron Gas. Physical Review, 136, B864. https://doi.org/10.1103/PhysRev.136.B864

[29] Segall, M.D., Lindan, P.J., Probert, M.A., Pickard, C.J., Hasnip, P.J., Clark, S.J. and Payne, M.C. (2002) First-Principles Simulation: Ideas, Illustrations and the CASTEP Code. Journal of Physics. Condensed Matter, 14, 2717. https://doi.org/10.1088/0953-8984/14/11/301

[30] Perdew, J.P., Burke, K. and Ernzerhof, M. (1996) Generalized Gradient Approximation Made Simple. Physical Review Letters, 77, 3865. https://doi.org/10.1103/PhysRevLett.77.3865

[31] Vanderbilt, D. (1990) Soft Self-Consistent Pseudopotentials in a Generalized Eigenvalue Formalism. Physical Review B, 41, 7892. https://doi.org/10.1103/PhysRevB.41.7892

[32] Monkhorst, H.J. and Pack, J.D. (1976) Special Points for Brillouin-Zone Integrations. Physical review B, 13, 5188. https://doi.org/10.1103/PhysRevB.13.5188

[33] Broyden, C.G. (1970) The Convergence of a Class of Double-Rank Minimization Algorithms 2. The New Algorithm. IMA Journal of Applied Mathematics, 6, 222 231. https://doi.org/10.1093/imamat/6.3.222

[34] Fletcher, R.A. (1970) A New Approach to Variable Metric Algorithms. Computer Journal, 13, 317.

[35] Goldfarb, D. (1970) A Family of Variable-Metric Methods Derived by Variational Means. Mathematics of Computation, 24, 23-26. https://doi.org/10.1090/S0025-5718-1970-0258249-6

[36] Shanno, D.F. (1970) Conditioning of Quasi-Newton Methods for Function Minimization. Mathematics of Computation, 24, 647-656. 
https://doi.org/10.1090/S0025-5718-1970-0274029-X

[37] Giudicelli, P., Roessli, B., Stunault, A., Ollivier, J., Amato, A., Sugawara, H. and Bernhoeft, N. (2004) Low Energy Magnetic Excitations in Superconducting $\mathrm{YbSnPd}_{2}$. Journal of Magnetism and Magnetic Materials, 272, E141-E142. https://doi.org/10.1016/j.jmmm.2003.11.086

[38] Adroja, D.T. and Malik, S.K. (1992) Magnetic-Susceptibility and Electrical-Resistivity Measurements on RPdSn (R = Ce-Yb) Compounds. Physical Review B, 45, 779. https://doi.org/10.1103/PhysRevB.45.779

[39] Malik, S.K., Umarji, A.M. and Shenoy, G.K. (1985) Depression of the Superconducting Transition Temperature of the Heusler Alloy $\mathrm{Pd}_{2} \mathrm{YSn}$ with the Addition of Magnetic Rare-Earth Metals. Physical Review B, 32, 4426. https://doi.org/10.1103/PhysRevB.32.4426

[40] Mullmann, R. and Mosel, B.D. (1998) Dimorphic YbPdSn with ZrNiAl and TiNiSi Type Structure. Z. Kristallogr, 213, 356-363.

[41] Simkin, M.V. and Mahan, G.D. (2000) Minimum Thermal Conductivity of Superlattices. Physical Review Letters, 84, 927. https://doi.org/10.1103/PhysRevLett.84.927

[42] Zhou, Z., Zhou, X. and Zhang, K. (2016) Phase Stability, Electronic Structure and Mechanical Properties of $\operatorname{IrBx}(\mathrm{X}=0.9,1.1)$ : First-Principles Calculations. Computational Materials Science, 113, 98-103. https://doi.org/10.1016/j.commatsci.2015.11.033

[43] Song, Y., Guo, Z.X., Yang, R. and Li, D. (2001) First Principles Study of Site Substitution of Ternary Elements in NiAl. Acta Materialia, 49, 1647-1654. https://doi.org/10.1016/S1359-6454(01)00052-0

[44] Wu, Z.J., Zhao, E.J., Xiang, H.P., Hao, X.F., Liu, X.J. and Meng, J. (2007) Crystal Structures and Elastic Properties of Superhard Ir $\mathrm{N}_{2}$ and $\mathrm{Ir} \mathrm{N}_{3}$ from First Principles. Physical Review B, 76, Article ID: 054115. https://doi.org/10.1103/PhysRevB.76.059904

[45] Gao, X., Jiang, Y., Zhou, R. and Feng, J. (2014) Stability and Elastic Properties of Y-C Binary Compounds Investigated by First Principles Calculations. Journal of Alloys and Compounds, 587, 819-826. https://doi.org/10.1016/j.jallcom.2013.11.005

[46] Ozisik, H., Deligoz, E., Colakoglu, K. and Surucu, G. (2013) Structural and Mechanical Stability of Rare-Earth Diborides. Chinese Physics B, 22, Article ID: 046202. https://doi.org/10.1088/1674-1056/22/4/046202

[47] Lewandowski, J.J., Wang, W.H. and Greer, A.L. (2005) Intrinsic Plasticity or Brittleness of Metallic Glasses. Philosophical Magazine Letters, 85, 77-87. https://doi.org/10.1080/09500830500080474

[48] Hill, R. (1952) The Elastic Behaviour of a Crystalline Aggregate. Proceedings of the Physical Society. Section A, 65, 349. https://doi.org/10.1088/0370-1298/65/5/307

[49] Fine, M.E., Brown, L.D. and Marcus, H.L. (1984) Elastic Constants versus Melting Temperature in Metals. Scripta Metallurgica, 18, 951-956. https://doi.org/10.1016/0036-9748(84)90267-9

[50] Pugh, S.F. (1954) XCII. Relations between the Elastic Moduli and the Plastic Properties of Polycrystalline Pure Metals. The London, Edinburgh and Dublin Philosophical Magazine and Journal of Science, 45, 823-843.

[51] Yan, H., Zhang, M., Wei, Q. and Guo, P. (2013) Ab Initio Studies of Ternary Semiconductor $\mathrm{BeB}_{2} \mathrm{C}_{2}$. Computational Materials Science, 68, 174-180. https://doi.org/10.1016/j.commatsci.2012.10.013

[52] Nye, J.F. (1985) Physical Properties of Crystals: Their Representation by Tensors 
and Matrices. Oxford University Press, Oxford.

[53] Zhang, Y., Franke, P., Seifert, H.J. and Wang, J. (2015) Polymorphism of $\mathrm{M}_{3} \mathrm{AlX}$ Phases $(\mathrm{M}=\mathrm{Ti}, \mathrm{Zr}, \mathrm{Hf} ; \mathrm{X}=\mathrm{C}, \mathrm{N})$ and Thermomechanical Properties of $\mathrm{Ti}_{3} \mathrm{AlN}$ Polymorphs. Journal of the American Ceramic Society, 98, 2570-2578. https://doi.org/10.1111/jace.13602

[54] Zhang, X., Luo, X., Li, J., Hu, P. and Han, J. (2010) The Ideal Strength of Transition Metal Diborides $\mathrm{TMB}_{2}(\mathrm{TM}=\mathrm{Ti}, \mathrm{Zr}, \mathrm{Hf})$ : Plastic Anisotropy and the Role of Prismatic Slip. Scripta Materialia, 62, 625-628. https://doi.org/10.1016/j.scriptamat.2010.01.009

[55] Ravindran, P., Fast, L., Korzhavyi, P.A., Johansson, B., Wills, J. and Eriksson, O. (1998) Density Functional Theory for Calculation of Elastic Properties of Orthorhombic Crystals: Application to $\mathrm{TiSi}_{2}$. Journal of Applied Physics, 84, 4891-4904. https://doi.org/10.1063/1.368733

[56] Clarke, D.R. (2003) Materials Selection Guidelines for Low Thermal Conductivity Thermal Barrier Coatings. Surface and Coatings Technology, 163, 67-74. https://doi.org/10.1016/S0257-8972(02)00593-5

[57] Cahill, D.G., Watson, S.K. and Pohl, R.O. (1992) Lower Limit to the Thermal Conductivity of Disordered Crystals. Physical Review B, 46, 6131 . https://doi.org/10.1103/physrevb.46.6131

[58] Li, C.X., Duan, Y.H. and Hu, W.C. (2015) Electronic Structure, Elastic Anisotropy, Thermal Conductivity and Optical Properties of Calcium Apatite $\mathrm{Ca}_{5}\left(\mathrm{PO}_{4}\right)_{3} \mathrm{X}(\mathrm{X}=$ $\mathrm{F}, \mathrm{Cl}$ or $\mathrm{Br}$ ). Journal of Alloys and Compounds, 619, 66-77. https://doi.org/10.1016/j.jallcom.2014.09.022

[59] Vassen, R., Cao, X., Tietz, F., Basu, D. and Stöver, D. (2000) Zirconates as New Materials for Thermal Barrier Coatings. Journal of the American Ceramic Society, 83, 2023-2028. https://doi.org/10.1111/j.1151-2916.2000.tb01506.x

\section{Submit or recommend next manuscript to SCIRP and we will provide best service for you:}

Accepting pre-submission inquiries through Email, Facebook, LinkedIn, Twitter, etc. A wide selection of journals (inclusive of 9 subjects, more than 200 journals)

Providing 24-hour high-quality service

User-friendly online submission system

Fair and swift peer-review system

Efficient typesetting and proofreading procedure

Display of the result of downloads and visits, as well as the number of cited articles

Maximum dissemination of your research work

Submit your manuscript at: http://papersubmission.scirp.org/

Or contact msce@scirp.org 